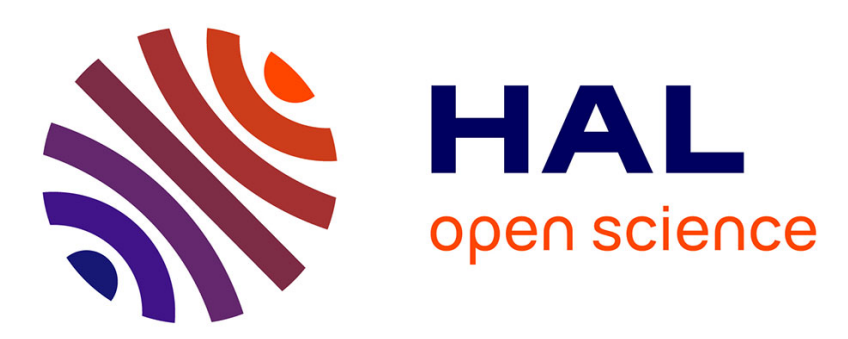

\title{
A Lasting Symbolic National Threat: The Dispute Over the Name Macedonia
}

Nikos Kalampalikis

\section{To cite this version:}

Nikos Kalampalikis. A Lasting Symbolic National Threat: The Dispute Over the Name Macedonia. Societies under threat: a pluri-disciplinary approach, 2020, 10.1007/978-3-030-39315-1_9 . hal02554635

\section{HAL Id: hal-02554635 \\ https://hal.univ-lyon2.fr/hal-02554635}

Submitted on 6 May 2020

HAL is a multi-disciplinary open access archive for the deposit and dissemination of scientific research documents, whether they are published or not. The documents may come from teaching and research institutions in France or abroad, or from public or private research centers.
L'archive ouverte pluridisciplinaire $\mathbf{H A L}$, est destinée au dépôt et à la diffusion de documents scientifiques de niveau recherche, publiés ou non, émanant des établissements d'enseignement et de recherche français ou étrangers, des laboratoires publics ou privés. 


\title{
Chapter 9 \\ A Lasting Symbolic National Threat: The Dispute Over the Name Macedonia
}

\author{
Nikos Kalampalikis
}

The naming dispute between Greece and the Republic of North Macedonia has been ongoing for over 25 years. These two countries claimed the same name, the former for its region, the latter for the entire country. Using the same name for both region and nation has been perceived by Greece as a collective symbolic threat. In this chapter, we will revisit the origins of this symbolic threat and recent developments, then discuss the issue from a theoretical perspective of social representations prompted by a psychosocial analysis. By examining a contemporary conflictual historic episode, we will demonstrate the symbolic effectiveness of social mental productions and their study as a way of expressing social thought. This vehicle for a collective cultural and historical imagination anchors onto layers of historical and cultural memory, and is a foundation for the construction and expression of a threatened national identity.

\section{Threatened by a Name}

The territory of the Balkans-with the geographical entity of Macedonia in the centre-is complex from an ethnological, linguistic and religious point of view. The demographic changes owing to historical circumstances which have played out in this region have caused ongoing instability to this day. Three antagonistic national narratives (Bulgarian, Serbian and Greek) have persisted in a dormant state for nearly fifty years. Then, the dissolution of Yugoslavia caused them to re-emerge in the same region. The end of the Yugoslav federation gave rise to new nation-states, which in their search for political and economic legitimacy, once again highlighted the latent,

\footnotetext{
N. Kalampalikis $(\varangle)$

University Lyon 2, Bron, France

e-mail: nikos.kalampalikis@univ-lyon2.fr 
violent power held by historical nationalisms. It was through this labyrinth, whose complexity is far from being described in detail here (see Kalampalikis, 2002, 2007), that the Socialist Republic of Macedonia achieved its independence in 1991.

On the eve of the Yugoslav war, the Yugoslav Socialist Republic of Macedonia reclaimed its autonomy and independence by referendum under the name of the Republic of Macedonia. Greece's reaction was instantaneous, refusing to accept this name on the grounds that firstly, it already belonged to one of its provinces in the north; and secondly, it emblematically represented part of its own cultural and historical heritage, namely the time of Alexander the Great. In addition, Greece condemned the use of hostile propaganda and some articles from the neighbouring constitution that seemed to potentially threaten its territorial integrity. Another element in the dispute was that not long afterwards, the neighbouring republic adopted a national flag decorated with the 'Star of Vergina', a star with sixteen rays on a red background historically associated with Alexander the Great's dynasty and geographically associated with a village in Greek Macedonia where it was discovered. In the meantime, approximately 45 countries had recognised the new republic under the provisional name the Former Yugoslav Republic of Macedonia - or even the Republic of Macedonia-based on the UN's decision made a few months earlier (it is now closer to 140 countries). For the Greeks, this was proof that their historical and cultural past was being usurped. Supported by the political authorities, thousands of people of all ages and political backgrounds demonstrated in the streets of major cities, flying the Greek flag and singing the national anthem. Participants' main slogans were: "Macedonia is Greek", "Macedonia is Greece" and "We don't want to sell our name". Dates, historical facts and old authors rose from their ashes. A glorious past was continually brought up, with Alexander the Great at the centre.

Between 1991 and 1995, a stormy social and political debate raged. The stakes were high: cultural and historical heritage, national symbols, territoriality and regional/national identity. The issue of this new country's name had become a threat, an objective one, but above all a symbolic threat to the imagination of an entire nation, likened to "stealing the Greek soul". Eventually, an intermediary agreement signed in 1995 established the conditions needed for political dialogue. This led to the Republic of Macedonia changing its flag and some articles in its constitution, and it was officially accepted into the United Nations under the provisional name of the Former Yugoslav Republic of Macedonia. ${ }^{1}$ Its name would remain provisional pending resolution with Greece for seven years.

From 1995 until just recently, diplomatic discussions between the two countries focusing exclusively on the name dispute never actually resulted in agreement, instead there was a climate of scepticism and media rumours. Several alternative names were proposed, including solutions for universal usage (by all countries, including Greece) and those strictly for use within Greece, and even now the name dispute seems to have been postponed indefinitely. In public discourse, the name chosen to describe the neighbouring republic is 'Skopje' and its inhabitants 'Skopjans'.

\footnotetext{
${ }^{1}$ Former Yugoslav Republic of Macedonia (FYROM).
} 


\section{A Nationalist Threat?}

Should we see an expression of nationalism underlying this threat posed by a name (Gerrits, 2016)? That would be to disregard the difficulty in defining a nation. According to Hobsbawm, the objective criteria often used to define 'nation' are as vague, shifting and ambiguous as the shape of clouds in relation to the earth's surface (1992, p. 15). Efforts to find a contemporary definition of nation thus come up against a paradox and a flaw for researchers. There is a strong, deep-seated declarative sentiment about national topics relating to their own sense of identity, without necessarily being able to objectively pinpoint what this sentiment, this form of identification, is exactly, nor how it differs from other possible forms of identification.

The same aporia can be found in social psychology with Tajfel (1969), in one of his papers on the formation of national attitudes. From the outset, the author does not hide his quandary in attempting to define 'nation', which incidentally he describes as a 'shadowy' concept. He concludes that "a nation is the largest, the most complex and abstract human membership group; and it is also a group which seems to be able to command at times a greater intensity of attachment than almost any other" (1969, pp. 143-144). Billig develops this idea and underlines that it is not only "natural" to have a national identity, it is "also something natural to remember" (1995, p. 37). Through this prism, Anderson (1991) described nations as "imagined communities". Communities need to be imagined, as their perception (temporal, spatial and human) greatly exceeds the immediate experience. Communities are distinguishable from each other not by their falsity or authenticity, but by the particular way in which each one goes about trying to represent itself as such. This representational spectrum reflects both the plurality and the singularity of the styles used to think about nation, embedded in specific socio-historical contexts and shaped by indigenous cultures. Thinking about one's own nation thus amounts to using the mental frameworks of a given society at a particular moment in time. These frameworks-vehicles for elements from local traditions and culture-convey an entire collective imagination about the national group that makes it unique, i.e., different.

\section{National Attitudes and Belief Systems}

Tajfel (1969, pp. 157-158) emphasised the cognitive and affective aspects of national attitudes, but also the formation of belief and value systems around the national idea, through the processes of social influence and identification. In this sense, the sine qua non of successful social communication is a population's acceptance of messages of a national nature. Direct proof that this kind of message has succeeded is particularly evident in the subjective perception of an assumed threat to the national membership group which is shared by the other members. This attitude "must be understood as a function of psychological mechanisms which transform the variety and multiplicity of social messages into a coherent cognitive and affective structure. One consists 
of simplifying, the other of "ideologising" the relevant aspects of the social (and sometimes also physical) environment" (Tajfel 1969, p. 168). Tajfel implicitly lays the foundations for a link between the idea of nation, social identity and social representation theory. These two levels of interpreting national attitudes (simplifying and ideologising) highlight a description — albeit an elementary one-of mechanisms for the formation of social representations, such as objectification and anchoring (Jodelet, 2015; Moscovici, 2013). We will come back to this, particularly anchoring.

\section{A Lasting Threat}

It was only very recently, last June, that a solution for the naming issue was attempted by the Greek government to help its neighbouring country in its efforts to enter NATO and the EU. A new name was proposed by the two prime ministers: 'Republic of North Macedonia'. This change, however, required various political steps (ratification by the Macedonian Parliament, then submission to a referendum, and ratification by the Greek Parliament once the acceptance has been officially acknowledged). Within the two countries, this attempt sparked many reactions, both popular and political. Many popular demonstrations took place in Greece, using slogans from 25 years ago, but nothing like the mass rallies of the past. Polls showed that $58 \%$ of Greeks interviewed took a negative view of the agreement between the two countries. In addition, in Athens, the head of Greek diplomacy resigned last October, the day after a heated meeting of the Council of Ministers during which he argued with the Minister of Defence, who has always been opposed to the recent agreement on the new name. This minister is also the leader of a small sovereigntist party within the government coalition, which is likely to move the country towards early legislative elections. In Skopje, the Prime Minister does not have the qualified majority to implement these changes, and the opposition has condemned the agreement, describing it as 'capitulation'.

More than half a century after the last phase of the conflict, the climate is once again sensitive and shifting. A significant point of contention, sharing a name presents major identity issues for each group, both vital and incompatible at the same time. This sense of identity forges a nation's knowledge, passed on through their history, teaching and shared symbols. It is an unthinkable name for Greek society, even today. The Macedonian issue shows the importance given to names, toponyms and ethnonyms, particularly when these convey key senses of identity for the group using them. The paradox of this matter arises from the fact that for both countries-Greece and the Republic of Macedonia - although via different processes, the name issue has the same focal reference: their national identity. Yet, they do not share the same representations of this identity. The Macedonian situation came about because a single name, with key senses of identity embedded in the memory and history of two peoples, has become an object of desire, disputes and grievances. The same word refers to a geographical area and an empire, an administrative province and an independent state, the inhabitants of one country and those of a province of 
another. A single word is brimming with meanings, memories, traditions, histories and identity-based, contradictory and antagonistic if not controversial content. This symbolic conflict is an illustrative example of the importance of studying the role of names and incorporating their historicity into social psychology, to better understand the processes involved in identity and memory in which they are inherent, thus contributing to a more comprehensive understanding of collective ideation. It also impels us to reflect on the theory behind one of the two major processes in the formation of social representations, anchoring.

\section{Principles of the Process of Anchoring}

The process of anchoring is as old as the theory of social representations. Alongside the process of objectification, it was proposed when the theory was first formulated as one of the two main mechanisms for the formation of social representations (see e.g., Jodelet, 2015; Kalampalikis, 2019; Moscovici, 1961, 2000, 2013; Rouquette \& Flament, 2005; Viaud, 2000). Just briefly, it is worth remembering here that the role of anchoring is to establish ties between new meanings from the social sphere and the stock of existing, culturally available and accessible knowledge. It is maintained through the need to reduce the element of uncertainty inherent in novelties (e.g., information, images, events, concepts, theories, people, groups, etc.), the desire to cope with the unknown represented by novelties and the desire to reduce the gap in understanding and communication about a given novelty. Metaphorically speaking, anchoring quenches our thirst for familiarising ourselves with the unfamiliar. In other words, through anchoring, representations enter society, becoming familiar for the group, while remaining dependent on earlier classification systems and existing networks of meaning. In turn, this already-there, this system of knowledge, influences the novelty's fate and degree of progressive integration by assigning it a priority (time), value (evaluation), hierarchy (classification) and name (naming). Thanks to its alliance and connection with this network, the new element becomes recognisable, imaginable and functional. In a word, it becomes representable - a social object capable of mediating interpretations within social groups. Familiarising oneself with an object, an idea or a person amounts to giving it/them meaning and existence. Conversely, something unclassified and unnamed is foreign, non-existent and, at the same time, threatening. In this article, I would like to focus on these pre-existing cognitive frameworks, the ultimate vehicles of transmission. Mental tools for understanding and interpreting the world and interacting with others, these culturally significant frameworks shape, dictate, anticipate and renew reality. These socio-cognitive categories offer models for the transmission, reading and interpretation of an inherently multifaceted and also increasingly complex reality. They largely contribute to forming and expressing social relations (through socio-cognitive processes such as classification, comparison, analogy, naming and prototypicality). 


\section{Beyond the Familiar}

A conservative vision of anchoring would involve reducing it to a simple normative meta-system. According to this vision, the new object in question would simply inherit the normative attributes of the category, giving it a loose, consensus-based meaning. Despite its newness, it thus becomes just another element amongst others; although new, it takes on most of the basic organisational principles of the category it has just joined. Mechanical incorporation, inward-looking dynamic change, passive transmission, etc., these are at least three characteristics of this vision.

An idealistic vision of anchoring would involve thinking of it as a peacekeeping mechanism, a stock of past knowledge into which a new functional element introduces itself and spreads. The latter imparts its novelty to the category, partially transforming the prototype and in the long term striving for an active transmission of the change. Two different visions — one static, the other dynamic-which nevertheless have one point in common, namely a certain policy of incorporating novelties, a 'positive' familiarisation policy. How then does one explain the persistence of a number of 'impossible' familiarisations, particularly those relating to otherness in all its forms (Jodelet, 2015; Kalampalikis, 2007) and the transmission of historically delicate periods? (Haas, 2002). One of the main functions attributed to anchoring is the domestication of the strange (Moscovici, 2013). Continuing with the metaphor, this presupposes categories that are open to novelty and the strange, categories characterised by a certain sense of hospitality. The rules of hospitality established by law in Athens and Rome required citizens to welcome strangers. They even advocated the exchange of half a symbol in the form of an object which would create a bond and a debt. However, at no time have the rules of hospitality ever meant accepting strangers under any other status than that of a stranger. Incorporating the novelty, familiarising oneself with the strange, yes, but always retaining the status of stranger. An opposite but relatively symmetrical procedure, this time leaning towards exclusion, was that of ostracism. Once again, an object - a shell or piece of pottery-was used to inscribe the name of the person the community had collectively decided to banish, to exclude, with no possibility of appeal either.

Disaffiliation from the familiar, defamiliarisation, recomposition and protection of the initial category. The words used by a society need that society to translate their intelligibility. We will now attempt to outline a hypothesis suggesting that the familiarisation traditionally attributed to anchoring can also work in the other direction, transmitting and guaranteeing the unfamiliar, ensuring that the unfamiliar remains so, thus establishing strangeness.

Familiarisation with novelty acts as a basic function of social representations, one of the true raisons d'être in social and mental life. Two fundamental processes dialogically transform knowledge into representation and social aspects into representation, objectification and anchoring. Metaphorically speaking, anchoring quenches our thirst for familiarising ourselves with the unfamiliar. In other words, through anchoring, representations enter society, becoming 'familiar' for the group, while 
remaining dependent on earlier classification systems and existing networks of meaning. In turn, this 'already-there', this system of knowledge influences the novelty's fate and degree of progressive integration by assigning it a priority (time), value (evaluation), hierarchy (classification) and name (naming). Thanks to its alliance and connection with this network, the new element becomes recognisable, imaginable and functional. In a word, it becomes representable - a social object capable of mediating interpretations within social groups. Familiarising oneself with an object, an idea or a person amounts to giving it/them meaning and existence. Conversely, something unclassified and unnamed is foreign, non-existent and, at the same time, threatening.

Revisiting the key concepts of the theory, in this chapter, we would like to focus on these pre-existing cognitive frameworks, the ultimate vehicles of transmission. Mental tools for understanding and interpreting the world and interacting with others, these culturally significant frameworks shape, dictate, anticipate and renew reality. These socio-cognitive categories offer models for the transmission, reading and interpretation of an inherently multifaceted and also increasingly complex reality. They largely contribute to forming and expressing social relations, supposing a certain policy of incorporating novelties, a 'positive' familiarisation policy. Resistance, inertia, friction, obstacles and threats can, however, jeopardise the incorporation of, the integration of and consequently familiarisation with the novelty. The strange can of course appear 'less' strange, which is undoubtedly less threatening, and more familiar than at first, without necessarily fully losing its status as strange. As how do you explain the persistence of a number of 'impossible' familiarisations, particularly those relating to otherness in all its forms (e.g., immigrants and the mentally ill) and the transmission of historically delicate periods? With the help of empirical examples, we will now attempt to illustrate a hypothesis suggesting that the familiarisation traditionally attributed to anchoring can also work in the other direction, transmitting and guaranteeing the unfamiliar, ensuring that the unfamiliar remains so, thus establishing strangeness.

\section{Familiarisation with the Unfamiliar}

Let us consider a classic example from Denise Jodelet's study on mental illness (1991). At this point, I would remind you that in a monograph that has since become a classic, this author emphasised the persistence and reinforcement of archaic belief on the contagion of madness within a particular community that lived with the mentally ill. This belief, which played roles of symbolically defending and protecting the community against a 'threatening' otherness, would be reactivated in spite of, or because of, the introduction of medication. It is as if interpretations of reality are set aside in the collective memory, never being completely erased in case some information comes to light that would make it useful, a kind of insurance against the unknown of the future (Jodelet, 2015, p. 33). This is an illustration of reverse familiarisation, of familiarisation with the strangeness of mental illness, which also resists 
any novelty that might call it into question. Here, transmission appears in the form of protection. Let us pause for a moment at another classic example, borrowed from phenomenology, from a text that Alfred Schütz himself entitled An Essay in Social Psychology. This includes two brief but outstanding articles by Schütz (2003), "The Stranger" and "The Homecomer", in which the author explores the issue of familiarisation, both for the person leaving their habitual collective frameworks of attendance, belonging and life, while remaining in the same cultural group (plurality of the intra difference), and for the foreigner returning to their country of origin. Both texts are characterised by a common aporia, that of a delicate, even impossible familiarisation, due to or despite the domestication of these initial categories. A similar but different social group is no more familiar than a primary group after a long absence. We posit that undoubtedly unlike scientific thinking, social thinking-particularly regarding otherness (Jodelet, 2015) — is not always compatible with 'positive' familiarisation.

This hypothesis was initially inspired by the study of the naming conflict presented at the start of the chapter (Kalampalikis, 2007). It has since been strengthened by other readings and studies (Apostolidis, Duveen, \& Kalampalikis, 2002; Kalampalikis, 2006, 2019; Kalampalikis, Jodelet, Wieviorka, Moscovici, \& Moscovici, 2019). This conflict reveals a rather palpable threat to the identity (and imagination) of two national groups and a risk of non-differentiation. Two national groups lay claim to a single name belonging to periods of history that were not learnt, transmitted or represented in the same way. In some of our findings relating to the name the Republic of Macedonia in Greek speech, we noted difficulties in naming, thinking, perceiving and classifying, in short, visualising the Other based on a name/label the group had decided to assign to it, i.e., 'Skopje/Skopjans'. These descriptions, conceived of and used exclusively by and for the national group, follow an identitarian strategy of relegating to otherness (Jodelet, 2015), aiming to render 'the Other' different, foreign, not to mention strange. Given that in their verbal responses, all our subjects referred to the Republic of Macedonia as 'Skopje', and its inhabitants 'Skopjans' - perfectly legitimate expressions in social discourse in Greece-the question about the name currently in common use seemed redundant. Instead, our attention focused on the name(s) our interviewees would like to see used to refer to this republic, in other words, on the name they themselves would prefer. Several subjects gave two or three different names, others only one; nearly all subjects excluded the presence of the word Macedonia, whether in grammatical or other form, in the proposed names. The current name for the Republic of Macedonia in Greek public discourse and common sense, i.e., 'Skopje', won the majority of polls of our subjects (53\%), including those originally from Greek Macedonia (61\%). 35\% of our subjects wanted to see an unspecified name that does not include the term Macedonia in a grammatical or any other form. Finally, only $11 \%$ of interviewees, composed exclusively of Athenians, said they prefer the current provisional name of the Republic of Macedonia in the form of the acronym FYROM, masking the controversial word and avoiding having to pronounce it.

On the basis of these results, plus the first two name preferences, we again note that the vast majority ( $88 \%$ ) expressed a desire to name the neighbouring republic something that does not include the term Macedonia. Moreover, we cannot fail to 
notice the absence of a more acceptable name to our subjects other than the artificial one of its capital. Following this, once the preferred name had been given, we asked the subjects to assign a nationality to these inhabitants, on the basis of this affirmation. In most cases, this question elicited surprise and sometimes embarrassment in interviewees. They needed to think for a few seconds, as if they had been asked a question they had never thought about and which suddenly seemed important. We mention this not to highlight our question, but to show and reflect as far as possible our subjects' surprise at a question to which they were accustomed to answering exclusively in the negative (non-Greeks), or with a denial of a tautology (Greeks = Macedonians). However, some of them eventually gave one or even several responses - one might say very interesting 'verified hypotheses'—regarding their neighbours' national affiliation.

Why 'verified hypotheses'? Quite simply because on interpreting the results, we noticed how difficult it was for our population to classify, to categorise its new neighbours into categories which were previously thought to be valid. Putting aside the admissions of ignorance ('I don't know'-22\%), affirmations in the negative ('Non-Greek'-11\%), and tautologies ('Skopjan'-14\%) that we commented on earlier, we would like to highlight the second most frequent response of 'Yugoslav' (20\%). This was mainly chosen by subjects originally from Greek Macedonia (31\% vs. $9 \%$ ) and clearly demonstrates the persistence of an earlier classification system as opposed to a new element ('Skopje'). The novelty of this element needs to be considered in context, as it has been around for approximately 50 years as the name of one of the six republics of the Yugoslav federation. However, several subjects admitted during the interviews that the name of the city was unknown to them, much more so than that of the republic. Furthermore, the new context of this classification, i.e., the naming issue between the two countries, makes this element different, giving it the appearance of novelty and strangeness, which as it touches on the sensitive issue of identity, is inevitably seen as a threat. Earlier in this article, I emphasised the fact that anchoring familiarises the strange and helps us understand the existence of a hierarchy and network of meaning, in line with the system of representations into which it is being integrated. In a way, considering 'Skopjans' as 'Yugoslavs' is refusing to abandon a classification that maintains the barriers of the past between the two groups' identity. An interviewee offered an explanation: "Greece has been Greece for years. Yugoslavia has been Yugoslavia for years. Yugoslavia broke up into all those states due to war. That does not mean it has ceased to be Yugoslavia."

Characterised by the controversy that created it, this oddity in turn makes it impossible to see the Other, impossible to imagine them in any other way than through the prism of identity-based antagonism. It creates a hysteresis and representation deficit that can be seen in our results through the impossibility for subjects to assign this littleknown or unknown population a nationality, through the embarrassment engendered when they attempted to classify it into a national and cultural category that might give it meaning, to situate it amongst others, and inevitably, in relation to themselves. The only socio-cognitive framework for familiarisation that was activated during this process was none other than its past representation, namely 'Yugoslav', a general category that maintains difference while neutralising all fear of danger. Our subjects' 
responses fit perfectly into Tajfel's succinct summary of 'we are what we are because they are not what we are' (1979, p. 183). An analysis of their discourse prompts us to supplement, or paraphrase, this maxim of identity by adding: we are what we are because we don't know who they are.

When discussing Halbwachs's notion of historical memory, Ricoeur noted that this included a progressive familiarisation with the unfamiliar and disturbing strangeness of the historic past (2004). This familiarisation is like a progressive anchoring, helping extend the scope of the experienced past to that of generational filiation. A concept that is anything but foreign to Moscovici's when he stated that "memory is the organ by which the unfamiliar is made familiar" (1993, p. 74). As the link between social representations and memory is established through conceptual affiliation to the process of anchoring, it is legitimate to wonder whether there is another function compatible with the one described earlier that operates in the other direction, ensuring that the unfamiliar remains unfamiliar. Considering the difference in othernesswhether this is in the tangible form of a group or person or abstract in terms of knowledge and thought-led Moscovici $(2002,2013)$ to make a distinction between two elementary forms of social thinking, stigmatic and symbolic thinking. Both deal with difference; however, for the former, this difference is thought of based on the principle of comparison and leans towards inferiority, whereas for the latter, the same difference is thought of in terms of recognition, thus without any connotation of hierarchical level. Using the distinction proposed by Moscovici, we might infer that this functions similarly to anchoring. One form of anchoring that is compatible with symbolic thinking and establishes familiarity, and a second form compatible with stigmatic thinking that establishes strangeness. Thus, in terms of transmission, a new form of familiarisation would appear, a familiarisation with strangeness - with what needs to remain foreign, strange, 'non-me' - to ensure, orchestrate or establish difference. These ways of experiencing the world-living, dynamic and permanentreveal to each of us the portion of the world in which we are participating without really acknowledging it. An acknowledgement of familiar strangeness. Such is the enigma of everyday life that philosophy, as well as social psychology, has long believed to be self-evident. As Bégout puts it, anyone who considers the everyday world to be limited to the unproblematic perpetuation of simply 'being there' is a victim complicit in their own mystification (Bégout, 2005, p. 46).

We have now outlined a hypothesis on anchoring, attempting to demystify the sometimes-irenic uses of this fundamental process and taking the opportunity to elaborate on the issue of names with respect to familiarisation. Demystifying familiarisation means admitting the tensions inherent in the objects we study (Kalampalikis \& Apostolidis, 2020). These tensions appear in a number of our objects of study, synonymous with their historicity and group appropriation, sometimes even their resistance to change and imperviousness to restrictive, threatening or contradictory information. A term, tension, which refers to one of the most significant definitions in social psychology, that of psychosocial perspective, including the association of ideas, and even taking the form of conflict to symbolise the dynamic nature of relations that govern the phenomena we face. 


\section{References}

Anderson, B. (1991/2016). Imagined communities: Reflections on the origin and spread of nationalism. London: Verso.

Apostolidis, T., Duveen, G., \& Kalampalikis, N. (2002). Représentations et croyances. Psychologie \& Société, 5, 7-11.

Bégout, B. (2005). La découverte du quotidien. Paris: Allia.

Billig, M. (1995). Banal nationalism. London: Sage.

Gerrits, A. (2016). Nationalism in Europe since 1945. London: Palgrave Macmillan.

Haas, V. (2002). La face cachée d'une ville. In T. Ferenczi (Ed.), Devoir de mémoire, droit à l'oubli? (pp. 59-71). Paris: Complexe.

Hobsbawm, E. (1992/2012). Nations and nationalism since 1780. Programme, myth, reality. Cambridge: Cambridge University Press.

Jodelet, D. (1991). Madness and social representation: Living with the mad in one French community. California: University of California Press.

Jodelet, D. (2015). Représentations sociales et mondes de vie. Paris: Éditions des Archives contemporaines.

Jovchelovitch, S. (2006). Knowledge in context. Representations, community and culture. London: Routledge.

Kalampalikis, N. (2002). Des noms et des représentations. Cahiers Internationaux de Psychologie Sociale, 53, 20-31.

Kalampalikis, N. (2006). Affronter la complexité: représentations et croyances. In V. Haas (Ed.), Savoirs du quotidien. Transmissions, appropriations, représentations (pp. 229-237). Rennes: PUR.

Kalampalikis, N. (2007). Les Grecs et le mythe d'Alexandre. Étude psychosociale d'un conflit symbolique à propos de la Macédoine. Paris: L'Harmattan.

Kalampalikis, N. (Ed.) (2019). Serge Moscovici: Psychologie des représentations sociales. Paris: Éditions des Archives contemporaines.

Kalampalikis, N., \& Apostolidis, T. (2020). Challenges for social representations theory: The sociogenetic perspective. In S. Papastamou (Ed.), New perspectives in social thinking and social influence. Montpellier: Éditions de la Méditerranée.

Kalampalikis, N., \& Haas, V. (2008). More than a theory: A new map of social thought. Journal for the Theory of Social Behaviour, 38(4), 449-459.

Kalampalikis, N., Jodelet, D., Wieviorka, M., Moscovici, D., \& Moscovici, P. (Eds.) (2019). Serge Moscovici: un regard sur les mondes communs. Paris: Éditions de la MSH.

Moscovici, S. (1961). La psychanalyse, son image et son public. Paris: PUF.

Moscovici, S. (1993). The return of the unconscious. Social Research, 60, 39-93.

Moscovici, S. (2000). Social representations. Cambridge: Polity Press.

Moscovici, S. (2002). Pensée stigmatique et pensée symbolique. Deux formes élémentaires de la pensée sociale. In C. Garnier (Ed.), Les formes de la pensée sociale (pp. 21-53). Paris: PUF.

Moscovici, S. (2012). Raison et cultures. Paris: Éditions de l'Ehess.

Moscovici, S. (2013). Le scandale de la pensée sociale. Paris: Éditions de l'Ehess.

Ricoeur, P. (2004). Memory, history. Forgetting: Chicago, University of Chicago Press.

Rouquette, M.-L., \& Flament, C. (2005). Anatomie des idées ordinaires. Paris: Albin Michel.

Schütz, A. (2003). L'étranger. Paris: Allia.

Tajfel, H. (1969). The formation of national attitudes: A social-psychological perspective. In M. Sherif \& C. Sherif (Eds.), Interdisciplinary relationships in the social sciences (pp. 137-176). Chicago: Aldine.

Tajfel, H. (1979). Individuals and groups in social psychology. British Journal of Social Psychology, 18, 183-190.

Tajfel, H. (1981). Human groups and social categories: Studies in social psychology. Cambridge: Cambridge University Press. 
Viaud, J. (2000). L'objectivation et la question de l'ancrage dans les représentations sociales. In N. Roussiau (Ed.), Psychologie sociale (pp. 89-100). Paris: In press.

Nikos Kalampalikis is Full Professor of Social Psychology at the University Lumière Lyon 2, France, and is member of the lab Social Psychology Research Group (GRePS). His current work on social representations deals with symbolic practices of kinship and gift. He recently co-authored, Social Representations and Life-Worlds (with Denise Jodelet); Serge Moscovici: Psychology of Social Representations; and Serge Moscovici: un regard sur les mondes communs. 